\title{
Development of production technology of rolling stock cast parts
}

\author{
Otabek Toirov*, and Nodirjon Tursunov \\ Tashkent State Transport University, Tashkent, Uzbekistan
}

\begin{abstract}
Using the computer simulation program ProCAST, the analysis of the processability of the gating system used in the current production of the SK "Foundry-Mechanical Factory" in the manufacture of large cast parts of railway rolling stock was performed. Based on computer modeling, a new design of a gating system with a dispersed metal motive with different sizes of feeder sections was developed, providing simultaneous parallel filling of all parts of the mold cavity. The feature of the proposed design of the gating system is the presence of an extended horizontal collector and the supply of metal to the end parts of the casting. With this design, two counter-flows are formed in the mold cavity, their fusion occurs in the middle part of the casting in a cooled and highly polluted state, since during the filling process, the head part of the flow collects sand inclusions along the way, is oxidized and saturated with hydrogen. These factors are a prerequisite for the formation of various defects in castings.
\end{abstract}

\section{Introduction}

Improving the operational and technological properties of industrial products, improving the technical level and quality of products is one of the main tasks of science and technology. The continuous tightening of the requirements for the reliability of the operation of structural elements makes it necessary to analyze in more detail the specific conditions of their operation. Most machine tools, machines and parts are subjected to cyclic loads during operation. Therefore, the problem of endurance of materials is relevant for the railway, automobile, aviation, shipbuilding, machine-tool construction, energy and other industries [1-8].

The main parts of freight cars produced by steel casting methods are the side frame and bolster of the bogie and elements of the traction device. The side frame of the bogie is subjected to maximum loads during operation. During operation, the side frames perceive static and dynamic vertical loads - from the weight of the railway carriage, from impacts when the railway carriage passes the unevenness of the track. In addition, tests are carried out for longitudinal loads from the traction force in case of uneven movement of the composition of wagons, efforts when wagons collide, and tests are also carried out for torque effect when wagons fit into curves [9-14]. At the same time, the main part of dynamic vertical loads is cyclical, and the fatigue strength of the side frames (the ability to

* Corresponding author: tv574toirov@mail.ru 
withstand the effects of cyclic loads for a long time) is the main characteristic of their operational reliability, i.e. it directly affects traffic safety.

Currently, on the territory of the CIS, a bogie of model 18-100 and its modifications is used as a freight car bogie. One of the main components of this design is the side frame because it combines a bolster, spring suspension, wheel sets with axle boxes and attachment braking equipment into a single system. The side frame is cast from 20GL steel according to GOST 34200-2013 [1].

One of the problems of the side frames is a fracture. During the operation of products, including frames, there are mainly two types of fracture - brittle and fatigue. The main factors contributing to these fractures are reduced mechanical properties of steel; shortcomings in the technology of smelting and deoxidation of steel; the imperfection of casting technology and casting of steel, leading to the formation of bulk structural defects and an increased number of non-metallic inclusions in the steel. During operation, a fracture of the side frame leads to economic losses and human casualties [15-22].

The side frame is structurally a thin-walled hollow casting with partitions, protrusions and L-shaped end parts that form box openings, where the wall interfaces have a radius $\mathrm{R}=55 \mathrm{~mm}$ (Figure 1).

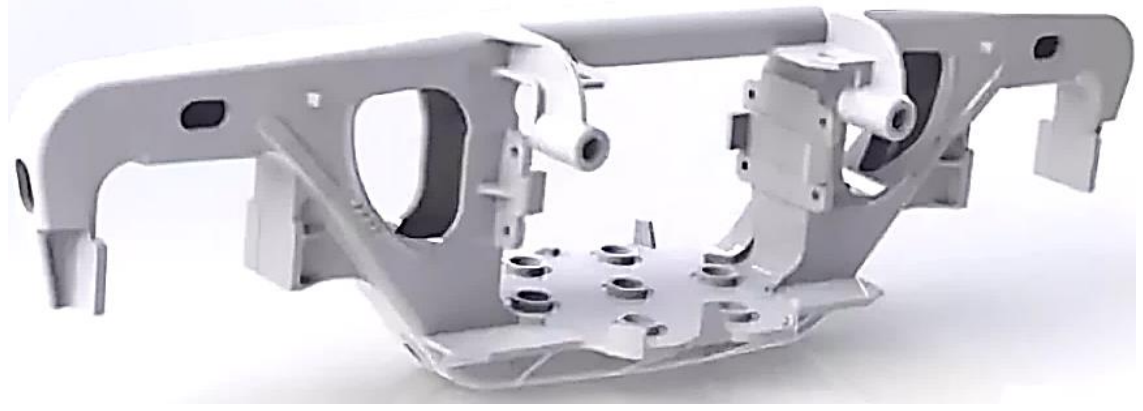

Fig.1. General view of the side frame casting

According to the current technology at the SK "Foundry-Mechanical Factory", the side frame is cast in sand molds using a gating system consisting of a riser, an extended horizontal collector and four feeders that supply metal to the end parts of the casting (Figure 2).

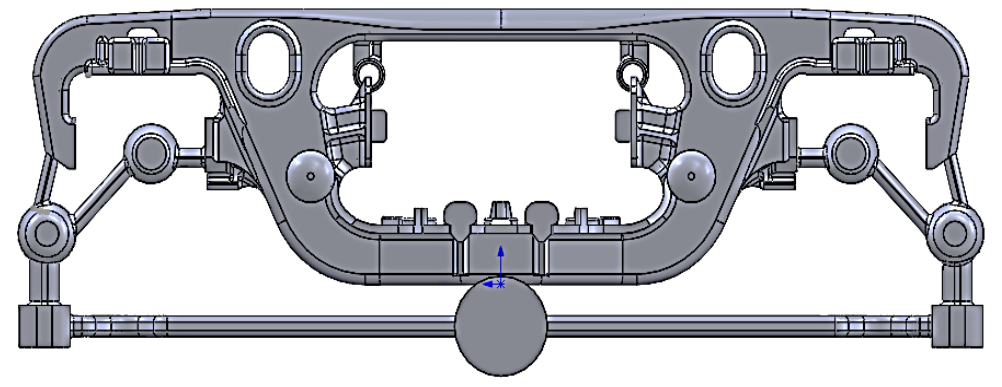

Fig.2. General view of the side frame with a gating system

The disadvantage of such a gating system is that filling the entire mold with liquid metal is carried out through the end parts of the casting, prone to crack formation. At the same time, two opposite flows are formed in the mold cavity; their fusion occurs in the middle part of the casting in a cooled and highly contaminated state, since during the filling process, the head part of the stream collects sand inclusions along the path, oxidizes and is 
saturated with hydrogen. These factors are a prerequisite for the formation of various defects in castings, especially non-ingots, sand and gas shells, and cracks [22-25].

Therefore, changing the structure of the side frame's sprue system to reduce the above defects is an urgent task.

\section{Methods}

Considering the results of the above analysis of the shortcomings of the current sprue system used to search for a more rational design, a 3D model of a cast side frame part was developed. Using the 3D model and the computer program "ProCast," the features of filling the mold cavity with melt, solidification and cooling of various casting parts are considered.

These processes were also imitated in the proposed gating system options. As the best option, the gating system was chosen, which provides fast and simultaneous filing of different parts of the mold cavity with a minimum run of liquid metal through it.

\section{Results and Discussion}

The study results of computer simulation of filling the mold with liquid melt through the gating system are shown in Figure 3.

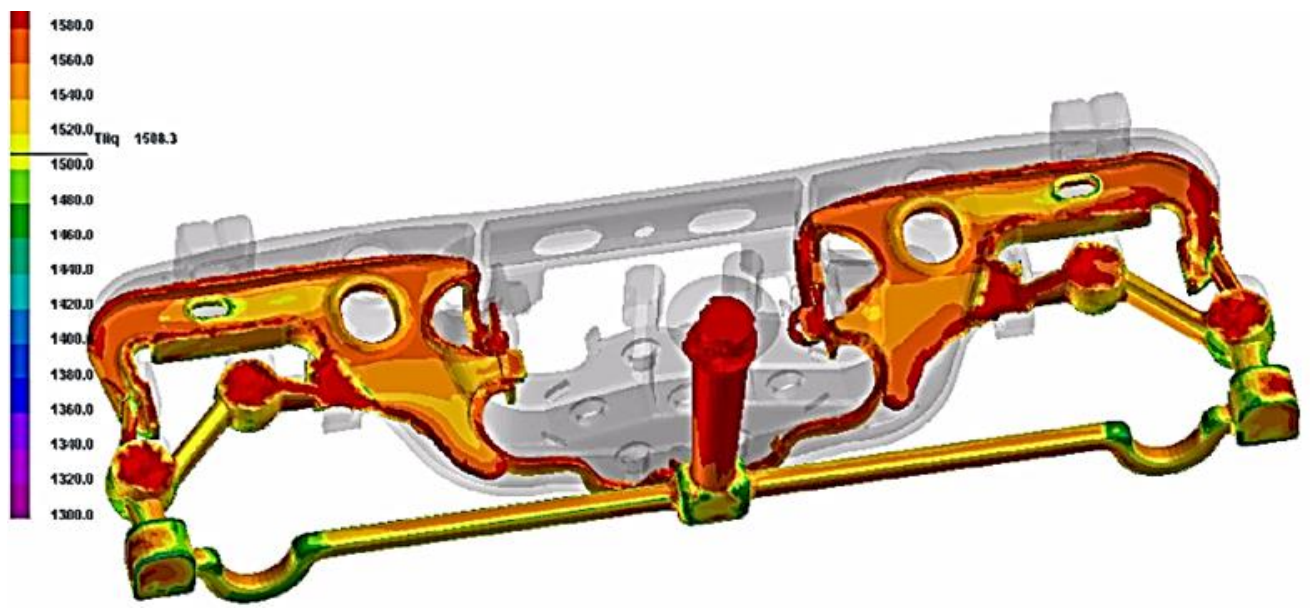

Fig. 3. Filling the mold cavity with liquid melt through the gating system according to the basic version

As can be seen from the figure, the filling of the mold begins with the fact that the melt from the riser passes into an extended collector and then through 4 feeders fills the casting cavity from the end parts. After their filling, the front of the current melt from each end part moves towards the opposite end part. As a result, two counter flows, having passed a long path, merge in the middle part of the casting.

When filling the mould cavity, liquid metal is known to contact the mould and rod surface and air and gases generated by the destruction of binders and the combustion of various process additives in the mould rod mixtures. In addition, along the melt flow path, it blurs the surface of molds and cores and picks up blockages. As a result, the head portion of the stream is most saturated with gases (hydrogen), oxidized and contaminated with sand inclusions. This factor is one of the significant drawbacks of the sprue system according to 
the basic version. It contributes to the formation of defects in the form of underfills, noningots, clogging, gas shells, non-metallic inclusions on the casting, etc.

A negative factor in the use of the gating system is strong local heating of the mold surface and the rods in the end parts ( $\mathrm{U}$ - shaped zones of the axle box opening) and filling the mold cavity in these parts with hot metal. This slows down the solidification process and the late formation of a solidified metal crust on the casting surface. These factors contribute to the formation of cracks, burning and shrinkage porosity on castings.

To eliminate the above disadvantages of the gating system, a new design of the gating system was developed according to the basic version (Figure 4), following the literature data, in which the collector is placed along the extended wall of the casting, the number of feeders is increased to six (a), and foam-ceramic filters are installed at the joints of the collector and feeders (b).

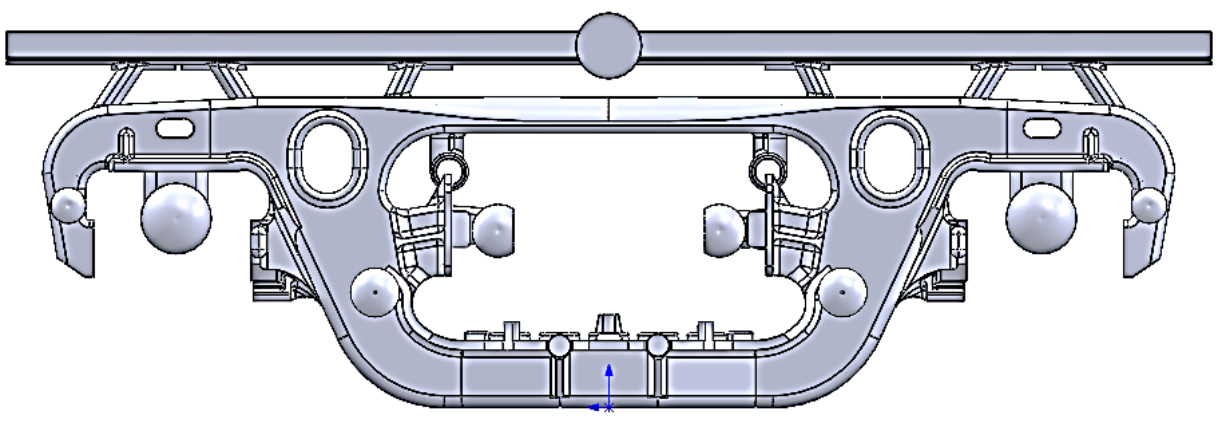

Fig.4. Proposed version of the gating system design

The proposed variant of the gating system design has a shorter length, and a larger number of feeders directed tangentially to the filled mold cavity. This provides a dispersed supply of metal to the casting. At the same time, the feeders have different sizes: the largest ones in proportion to the permeable volume of the melt have feeders closest to the riser, and the smallest ones have extreme lateral ones. This is necessary to achieve simultaneous parallel filling of all mould cavity parts (Figure 5). The required cross-section dimensions of the gate system elements and filters are determined by the method.

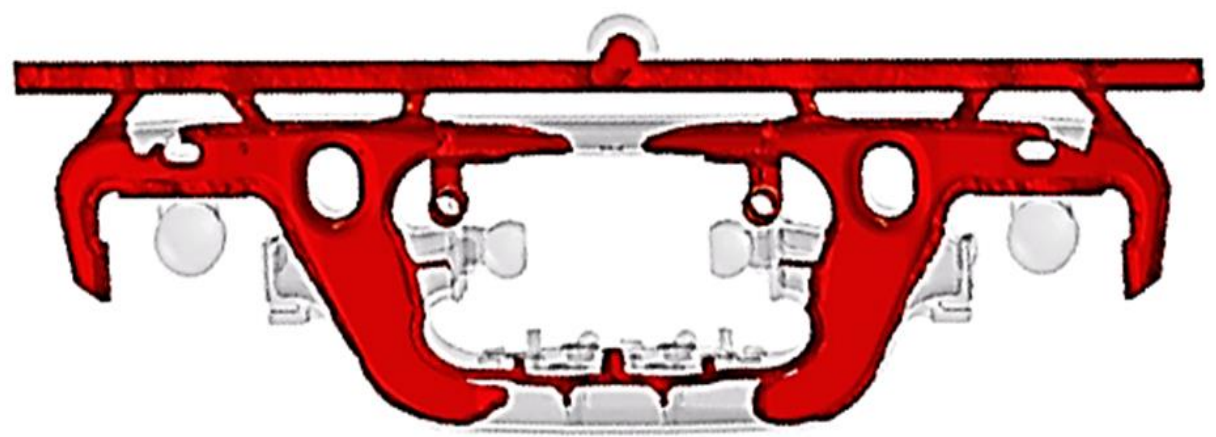

Fig. 5. Filling the mold cavity with liquid steel through the gating system

The proposed version of the gating system design for the side frame has obvious advantages. It is less extended, at the same time, a shortened path for delivering liquid steel to the cavity to be filled, as well as a dispersed metal feed with different sizes of crosssections of the feeders and filling the mold cavity with filtered metal. At the same time reduces the consumption of metal on the gating system. Such a technical solution will 
undoubtedly significantly reduce the defects of the cast side frames and increase the costeffectiveness of their production.

\section{Conclusions}

Using the computer simulation program ProCAST, the analysis of the manufacturability of the design of the basic gating system, which is used in the current production when casting the side frame of railway transport, is performed. A feature of the basic gating system is the supply of liquid metal to the end parts using an extended collector. In this case, the mould filling with liquid metal is carried out through the end castings, prone to cracking. At the same time, two opposite flows are formed in the mold cavity; their fusion occurs in the middle part of the casting in a cooled and highly contaminated state, which contributes to the formation of various defects in the castings.

The concentrated supply of metal to the end parts of the casting leads to strong local heating of the mold surface and the rods in the U-shaped zones of the axle box opening. In this case, the mold cavity in these zones is filled with a hotter metal. This leads to a slowdown in the solidification process and the late formation of a hardened metal crust on the casting surface. These factors contribute to the formation of cracks, burnout, and shrinkage porosity on castings.

Considering the above, a new design of a gating system with a dispersed metal lead with different cross-section sizes of feeders, providing simultaneous parallel filling of all the frequent mold cavities, has been developed. At the same time, liquid metal enters all feeders through a foam-ceramic filter installed at the junction of the collector and the feeder. Such a technical solution will undoubtedly provide a significant reduction in the defect rate of cast side frames and increase the yield of suitable castings.

\section{References}

1. GOST 32400-2013. Side frame and bolster cast for bogies of railway carriage. Technical conditions. - Official edition. - M .: Standartinform, (2014).

2. Senko, M.I. Pastukhov, S.V. Makeev, I.F. Pastukhov, Analysis of the causes of damage and the possibility of extending the service life of the side frames of freight railway carriage bogies, "Belarusian State University of Transport", March 29, (2010).

3. Savchuk V., Zobov G. Radius of break at the Council of chief designers. Railway engineering. (2). (2013).

4. Kuleshov A.V., Lotsan E.A., Mikhalchishin S.V., Tsvik L.B, Analysis of the stressstrain state of the side frame of a bogie, Irkutsk State Transport University, pp. 18100 .

5. Kozlov L.Ya „, Kolokoltsev VM, Vdovin KN. et al. / Under rd. L. Ya. Kozlov, production of steel castings, Textbook for universities, p 352, (2013).

6. Ten E.B., Kimanov B.M., Runov O.V. Calculation of the gating system with a filtering element, Foundry of Russia, (12), p. 43-46. (2005).

7. A Tayeb Mohammed, Fruehan Richard, Sridhar Seetharaman, Dephosphorization in the DRI-EAF Steelmaking and the Effect of Alumina, AISTech Proceedings, p. 10731086. (2014).

8. Tursunov N.K., Semin A.E., Sanokulov E.A. Study of dephosphorization and desulfurization processes during steel smelting 20GL in an induction crucible furnace with further processing in a ladle using REM, Black metals, (1). p 33-40. - 2017.

9. Tursunov N.K., Semin A..E, Sanokulov E.A. Research in laboratory conditions and an induction crucible furnace with a capacity of 6 tons of refining mode for $20 \mathrm{GL}$ steel in 
order to improve its quality, Heavy Machine Building, (1-2). p. 47-54. (2017).

10. SolntsevYu.P., Andreev A.K., Serditov A.E. Cold-resistant and wear-resistant casting steels. St. Petersburg: Khimizdat, p 336, (2007).

11. L.Ya. Kozlov, V.M. Kolokoltsev, K.N. Vdovin, Production of steel castings, Textbook for universities M .: MISIS, p 352. (2005).

12. V.M. Kolokoltsev, V.V. Bakhmetyev, K.N. Vdovin, Smelting high-quality steel for shaped casting, Textbook by. Magnitogorsk: MSTU, p 268. (2007).

13. Shapovalov A. N. Theory of metallurgical processes. Educational and methodical manual. Novotroitsk: NF NUST MISIS, p 91. (2015).

14. A.V. Lakedemonsky, F. S. Kvasha, Ya. I. Medvedev, Foundry defects and methods of their elimination, M.: Mashinostroenie, p 152. (1972).

15. Sokolov G. A, Extra-furnace refining of steel. M: metallurgy, p. 208. (1977).

16. Kolokoltsev V. M., Bakhmetyev V. V., Vdovin K. N.,Smelting of high-quality steel for shaped casting, Magnitogorsk: MSTU. p. 268. (2007).

17. Kozlov L. Ya. Kolokoltsev V. M., Vdovin K. N., Ten E. B, Production of steel castings, Magnitogorsk: MSTU.- p 352, (2011).

18. Ten E.B., Kimanov B.M., Kalashnikov A.I. Influence of filtration on the properties of steel treated with REM, Foundry, (12). (1989).

19. Dobrynina A.V. Optimization of the composition of cast low-carbon steel in order to reduce the cold brittleness of castings, Abstract diss. Cand. tech. sciences. Krasnoyarsk. KSTU. p 24. (2003).

20. Khasanov B., Vatin N., Mirzaev T., Suyunov A., Radjabov M. Physicochemical fundamentals of modifying concrete mix and concrete, IOP Conference Series: Materials Science and Engineering, 2021, 1030(1), 012022

21. SolntsevYu.P., Andreev A.K., Grechin R.I. Foundry cold-resistant steels. M.: Metallurgy. p 176. (1991).

22. Adilkhodjaev A., Hasanov B., Shaumarov S., Kondrashchenko V. Aerated concrete with predetermined pore parameters for the exterior walls of energy efficient buildings, IOP Conference Series: Materials Science and Engineering, 2021, 1030(1), 012006

23. Lakedemonsky A.V., Kvasha F.S., Medvedev Y.I, Casting defects and ways to eliminate them etc. M.: Engineering. p 152. (1952).

24. Rybakov V., Jos V., Raimova I., and Kudryavtsev K. Modal analysis of frameless arches made of thin-walled steel profiles. IOP Conf. Ser. Mater. Sci. Eng. 883, (2020).

25. Kattakulov F., Muslimov T., Khusainov A., Vokhidov O., Sultanov S. Water resource saving in irrigation networks through improving the efficiency of reinforced concrete coatings, IOP Conference Series: Materials Science and Engineering, 883(1), 012053, (2020) 